\title{
Consumer Attitude toward Marketing and Subjective Quality of Life in the Context of a Developing Country
}

\author{
Mark Peterson and Ahmet Ekici
}

The purpose of this research is to better understand Consumer Attitude toward Marketing (CATM) and how it relates to quality of life (QOL) in a developing country. Such sentiments toward marketing practice are core indicators of the marketing system's performance in delivering wellbeing to consumers during the first stage of the consumption process-acquisition. In this stage, the activities of businesses are set in high relief for consumers. As Douglas and Craig (2006) have noted how marketing is sadly neglected in developing countries, the Consumer Attitude toward Marketing (CATM) measures suggest how QOL-marketing might correlate with $Q O L$ in developing countries. Measures used in Gaski and Etzel's (1986) Index of Consumer Sentiments toward Marketing (ICSM) are enhanced and refined in this study of Turkish consumers. Using a confirmatory-factor-analysis approach, these measures are then used to derive a second-order factor representing CATM and to assess its nomological relationship with subjective quality of life (QOL).

Keywords: consumer attitude toward marketing; sentiments toward marketing; consumer well-being; quality of life

QOL-marketing is the business mechanism that plans, prices, promotes and distributes economic consumer goods to consumers in ways to maximize consumer well-being.

—Sirgy et al. 2006, 412

Macromarketing is involved in comprehending, explaining, and predicting the effects that the marketing system can have, and is having, on the world (Wilkie and Moore 2006). As globalization increasingly integrates markets, nationstates, and technologies, the world becomes a place where marketing systems in the developing world matter more and more to marketers (Prahalad 2005). Yet, Douglas and Craig (2006) note that the role of marketing in developing countries is sadly neglected. Marketers and researchers must apply much more effort to better understand consumers in these developing countries, because the lower incomes, lack of consumer information, and poorly developed marketing infrastructure suggest that relevant issues may be strikingly different. In sum, those interested in how successful QOLmarketing might be accomplished in developing countries must gain better understanding of consumer views of the marketing system in which these consumers currently participate.

The purpose of this research is to better understand Consumer Attitude toward Marketing (CATM) and how it relates to subjective quality of life (QOL) in a developing country. Currently, researchers interested in consumer wellbeing (CWB) have few empirical studies to suggest how aspects of CWB, such as evaluations of marketing practices in a society, might be (1) distinct from QOL, and (2) related to QOL. Such sentiments toward marketing practice are core indicators of the marketing system's performance in delivering well-being to consumers during the first stage of the consumption process-acquisition. In this stage, the activities of businesses are set in high relief for consumers. The study presented in this article focuses on consumer perceptions of important activities of businesses, such as (1) provision of goods and services, (2) advertising, (3) pricing, and (4) retailing environments. Measures used in Gaski and Etzel's (1986) Index of Consumer Sentiments toward Marketing (ICSM) offer researchers a widely accepted and readily understood approach to gauge citizen experiences as consumers in a society. For this reason, the ICSM measures are employed in this study and serve as the foundation for identifying measures that would best capture the experience of being a consumer in a developing country.

\section{GASKI AND ETZEL'S ICSM}

Gaski and Etzel's ICSM measures are taken from the vantage point of those experiencing consumption in the

Journal of Macromarketing, Vol. 27 No. 4, December 2007 350-359 DOI: $10.1177 / 0276146707307125$

(C) 2007 Sage Publications 
markets of a country and represent the society's consumer experience with the major efforts of marketing practice (Gaski and Etzel 2005; Gaski and Etzel 1986). The ICSM is a composite of four multi-item Likert-type scales each corresponding to one of the four elements of marketing practice anchoring the acquisition stage of consumption-product, price, promotion (especially advertising), and distribution (manifested by retail service). The original theoretical rationale for using these dimensions was simply to understand how consumers in a society evaluated marketing practice in the four fundamental dimensions of marketing management (product, price, promotion, and place- the " 4 P's") postulated by McCarthy (1960).

Using large-scale sampling with an annual sample of 2000 and response rates of at least 53.8 per cent, marketing research professionals have collected ICSM data each year since 1984 . In this way, researchers have sought understanding for the effectiveness of businesses in a society's Aggregate Marketing System (AGMS) (Wilkie 2006). While government and nonprofits also are conceptualized as participating in the AGMS, in most all societies today, the major portion of activity in the AGMS is represented by businesses serving consumers.

Importantly, the Gaski and Etzel scales have shown high reliability and generalizability in studies both in the United States and abroad (Varadarajan and Thirunarayana 1990). Researchers have employed the ICSM outside the United States in locales such as Hong Kong, Australia, and China (Wee and Chan 1989; Chan, Yau, and Chan 1990; Chan and Cui 2004). In general, the Chinese reported slightly more favorable attitudes toward marketing practice than consumers in the United States, while the Australians reported slightly less favorable attitudes than consumers in the United States.

Over the past two decades, the series of annual measurements reported by Gaski and Etzel (2005) suggest a slight upward trend in U.S. consumers' sentiment toward marketing practice. The most favorably rated practice of marketing is distribution/retailing, then product, advertising, and finally price. Research shows that changes in the national economic environment (as measured by inflation and savings rate) are negatively related to changes in the ICSM.

\section{Business Provision}

A country characterized as high on consumer well-being is one in which most of its people's basic needs are met and have access to goods and services to meet their non-basic needs.

—Sirgy et al. 2004, 269

Fisk (1981) has described the marketing system as a "life support provisioning technology" for society. Slater et al. (1969) had adopted this view and further reinforced a conceptualization of marketing to be broader than just the narrow activities one firm might have to identify customer needs and to meet these needs better than competitors (Nason and White 1981). Dixon (1984) later used this idea in his systems approach to macromarketing. To Fisk, Slater, and Dixon, marketing should be considered as a societal activity wherein the aggregation of all firms' marketing activities could be understood as a provisioning system for society.

Recently, a similar view to those of Fisk and Slater has been heard from within the ranks of enlightened business practitioners. From his vantage point as Worldwide Director of McKinsey \& Company, Ian Davis $(2005,75)$ asserts that CEOs would do well to articulate a purpose for business in less dry terms than "shareholder value." According to Davis, business' ultimate purpose is "the efficient provision of goods and services that society wants." As a result of this conceptual convergence between seminal macromarketing scholars and thought leaders in business today, there is a greater appreciation for the role of businesses in delivering consumer well-being. Accordingly, a construct for measuring what businesses provide to meet consumers' wants has been conceptualized as "business provision."

At the societal level, Business Provision consists of the core products or services delivered to customers by businesses. These private goods are distinct from the public goods and services provided by other sectors, such as non-governmental organizations (unions, consumer rights groups, environmental advocacy groups), and governments (of municipalities, of states, of nations, and transnational organizations) (Klein and Nason 2000). Additionally, the context for shopping is included in this conceptualization because this is a demonstrated want of consumers, as well. Consumers not involved in self-production depend on businesses to provide the private goods they want. Such consumers desire shopping or search experiences that are pleasing. Such experiences are inextricably linked to the products sought by consumers. In a competitive market it is hard to imagine that consumers would seek quality goods and would insist on an accompanying shopping experience that was displeasing.

Whereas, the product dimension of the ICSM represents defects or quality of products, business provision is broader in scope. Business provision represents not only the utility of a firm's core offerings, but the value of the added features and enhancements, as well as consumer choice in these offerings. In this way, the construct of Business Provision is a centerpiece of the acquisition dimension of consumption.

In their empirical research of Chinese consumers, Chan and Cui (2004) derived a second-order factor based on the ICSM items. This second-order factor was proposed to represent "Consumer Attitude toward Marketing." However, the low fit of the confirmatory factor analysis model $(\mathrm{CFI}=.821)$ and the relatively low factor loadings of the items on the firstorder factors (ranging from .28 to .68) suggests that the model needed further refinement. The authors of this article propose that more rigorous scale development including item pruning, as well as the inclusion of items representing 
Business Provision would provide a better model of CATM in the developing country context than what Chan and Cui were able to measure using the ICSM items alone. Accordingly, the first research question posits the possibility of improved measurement of Consumer Attitude toward Marketing in the developing country context:

Research Question 1: What will be the underlying structure of CATM in the context of a developing country?

\section{Consumer Well-Being}

Lee et al. (2002) developed a subjective measure of consumer well-being by reviewing proposed domains for consumer life and then rendering a consumption process model that included five dimensions covering the cycle of consumptions activities. These dimensions were (1) acquisition, (2) consumption, (3) possession, (4) maintenance, and (5) disposition. (Recently, a sixth dimension has been added-preparation [Sirgy and Lee 2006]). Based on the bottom-up spillover theory and empirical evidence, Lee et al. (2002) hypothesized that CWB would predict life satisfaction (QOL). Composite indexes consisting of multiple items for each of the five domains were used. Using a convenience sample of university undergraduate students, a single-item measure of life satisfaction was employed (Lee et al. 2002). Results of regression analysis suggested that the acquisition, possession, and consumption dimensions were positively related to the dependent variable of life satisfaction. This was a promising empirical finding which linked some of the CWB dimensions with QOL. On close scrutiny of the ICSM items, it can be seen that most all of the ICSM items and the Business Provision items focus on the acquisition dimension in the cycle of consumption. Importantly, this dimension was one of the CWB dimensions found to be related to QOL in Lee et al.'s 2002 study.

\section{QOL}

The work of Lee et al. (2002) showed empirical support for life satisfaction being an important consequence of consumer well-being. Here, life satisfaction was represented by a single-item measure. Multi-item measures of subjective quality of life have been used with success in international research. For example, Diener et al.'s (1985) Satisfaction with Life Scale (SWLS) has been widely employed in psychological research and has consistently displayed good reliability and validity (Burroughs and Rindfleisch 2002). The SWLS has been employed in dozens of countries (Diener and Suh 1999). Norms for a seven-point SWLS have ranged from 4.0 in China to 6.23 in Australia. Turkey and the United States place in the middle of countries with 5.29 and 5.77, respectively. The SWLS is a five-item measure that is intended to assess cognitive aspects of well-being and includes such items as "The conditions of my life are excellent" and "I am satisfied with my life."

Malhotra (2006) has called researchers to better understand the nature of the QOL construct. Accordingly, the second and third research questions of the current study address the convergent and discriminant validity of CATM and QOL, as well as the relationship between CATM and QOL:

Research Question 2: Can CATM and QOL be considered to be distinct constructs?

Research Question 3: Can it be shown that CATM and QOL are related?

\section{DEVELOPING COUNTRY CONTEXT OF THE STUDY}

Turkey offers a valuable vantage point for researchers considering macromarketing issues related to developing countries. Turkey is classified as a Middle Income Country (such countries have a 2001 Gross National Income [GNI] per capita between $\$ 746$ and $\$ 2,975$ ). Turkey's GNI per capita was $\$ 2,530$ in 2003, ranking it ninety-third among the world's countries on this measure of output (World Bank 2003). Table 1 presents a comparison of Turkey and the United States on macro-economic indicators. As can be seen in this crosssectional view, Turkey's economic profile shows higher growth and higher inflation, but less income per capita. The following historical notes provide a context for better understanding current conditions of consumer well-being in Turkey.

Capitalism, industrialization, modern marketing, and consumer culture have emerged in Turkey especially with the adaptation of the liberal policies just before the collapse of the Ottoman Empire (1903 to 1923) and during the early years of post-Ataturk era (1940 to 1950) with high state ownership and control of production and distribution of goods and services (Karababa 2006). During the contemporary era (the second part of the twentieth century), marketing and consumption activities have been shaped by economic, cultural, social, and political forces. Turkey has seen her most neoliberal economic policies right after the 1980 military coup.

Since 1980, the Turkish economy has experienced a substantial increase in the production of consumer goods, particularly durables such as refrigerators, washing machines, electronics such as TVs and stereos, and motor vehicles. The increased interest by the global companies had its impacts on both export and import operations, and on the adaptation of the modern marketing practices. Turkey's entrance into the European Customs Union in 1996 created an immediate demand for newly available consumer goods. As a result, the domestic consumer goods sector grew 20 percent between 1996 and 1999 (Karababa 2005). 
TABLE 1

COMPARATIVE STATISTICS FOR THE US AND TURKEY FOR 2005

\begin{tabular}{|c|c|c|c|c|c|}
\hline Country & $\begin{array}{c}\text { Population } \\
\text { (Millions) }\end{array}$ & $\begin{array}{c}\text { GDP } \\
\$ \text { Per Capita }\end{array}$ & $\begin{array}{c}\text { GDP \% } \\
\text { Composition by Sector }\end{array}$ & Annual Real Growth & $\%$ Inflation \\
\hline United States & 298 & 41,800 & $\begin{array}{l}\text { agriculture: } 1.0 \\
\text { industry: } 20.7 \\
\text { services: } 78.3\end{array}$ & 3.2 & 3.5 \\
\hline Turkey & 70 & 8,200 & $\begin{array}{l}\text { agriculture: } 11.7 \\
\text { industry: } 29.8 \\
\text { services: } 58.5\end{array}$ & 5.6 & 7.7 \\
\hline
\end{tabular}

Importantly, Turkey has reigned in double-digit inflation in recent years. However, its standard of living represents that of a developing country experiencing industrialization. Its 2004 Human Development Index ranking was ninetysecond, which places it in the category of Medium Human Development (UNDP 2006).

\section{METHOD}

\section{Scale Development Overview}

Following the work of Malhotra (1981), scale development was pursued in a sequential fashion. The six steps of this protocol are presented in figure 1 . While step 1 was discussed in the previous section, steps 2 through 6 are presented in the following paragraphs. In step 2, Gaski and Etzel's (1986) ICSM served as the source of items addressing macro-level assessments of marketing practice covering product, price, promotion, and distribution. Additionally, three items addressing the shopping experiences, products, and services that consumers want and that businesses provide were included. Finally, the five-item Satisfaction with Life Scale was included to assess the distinctiveness of the CATM and QOL constructs. In total, twenty-eight items were identified to measure CATM and QOL. All items in the study were measured using five-point Likert-type scales.

In step 3, Turkey was selected as the study domain for developing countries. In step 4, a survey was conducted with a broad cross-section of Turkish consumers twenty-one years of age and older. In step 5, data analysis was performed, which resulted in a final list of seventeen items identifying five constructs. In step 6, confirmatory factor analysis using structural equation modeling derived a second-order factor representing CATM. This second-order factor was then allowed to be correlated with QOL. In total, the model included six constructs.

\section{Selection of Setting}

The study presented in this article focused on measuring CATM and QOL in the context of a developing country. Toward this end, Turkey was chosen as a setting of the study

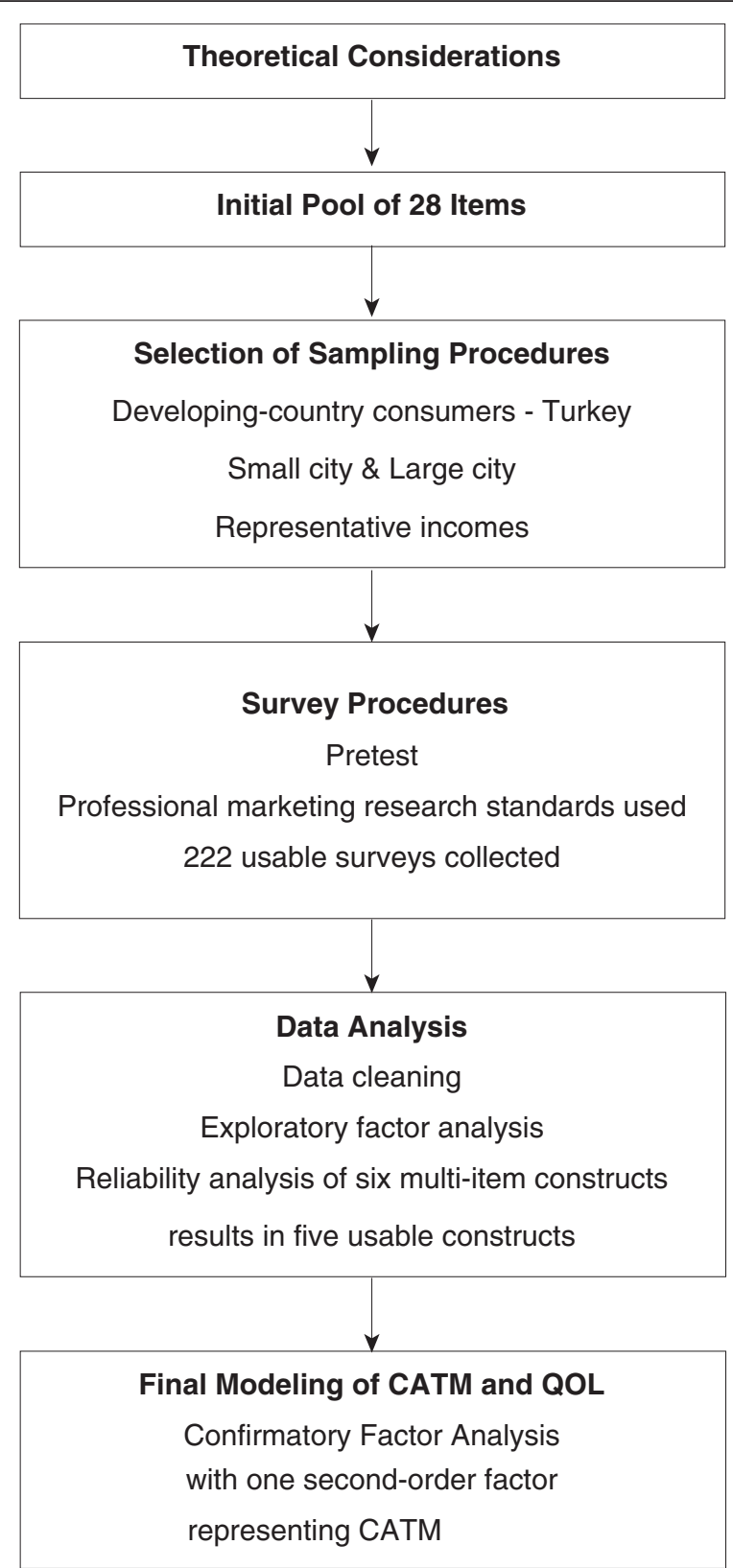

FIGURE 1 FLOW CHART OF THE SCALE DEVELOPMENT AND MODELING PROCEDURES 
for the reasons previously specified. To ensure the vantage points of consumers from different regions and different city sizes, data collection was undertaken in two cities. Half of the respondents came from the capital city of Ankara (2006 population of approximately four million), and the other half came from a small coastal city on the Black Sea in the northern part of the country-Ereğli (2006 population of more than 90,000). In terms of demographic profile, the groups of respondents from these two Turkish cities were very similar.

\section{Survey Procedures}

Prior to survey administration, the survey instrument was pretested with ten undergraduate students at a Turkish university. Adjustments were made to improve clarity of the wording for some questions. Then, parallel translation into Turkish was made by a professional translation company in Turkey using both native English and native Turkish speakers (Malhotra, Agarwal, and Peterson 1996).

The survey was administered at several locations in the two cities. Quota sampling based on age was used. A judgmental sampling procedure was used by field workers to fill the quotas that would ensure a broad cross-section of Turkish consumers. A small cash incentive was given to those who completed the survey. For some consumers contacted at their place of work, field workers had to return the next day to pick up surveys that had been dropped off the previous day. To ensure quality of data collection, marketing research industry standards were employed. In addition to meeting standards for training interviewers and monitoring the data collection effort, 20 percent of the respondents were phoned during the week after completing the survey and asked about their experience. In general, respondents reported a favorable experience.

\section{RESULTS}

The survey procedures resulted in 222 usable surveys. Males composed more than 62 percent of respondents. About one-half of the respondents were married. About one-half of the respondents were in the twenty-one to thirty age group. The modal value for education level was "high school graduate." Seventy-one percent of respondents reported working outside the home on a regular basis. The modal value for monthly household income was 501 to 1,500 New Turkish Lira (approximately $\$ 300$ to $\$ 1,000)$. Importantly, this matches the average household income across Turkey. Table 2 presents details on the demographic characteristics of the sample group.

Table 3 presents a comparison between the Turkish respondents in this study and the most recent norms for the United States on the ICSM. The norms for each dimension are computed by converting scales (to a format of -2 to +2 ),
TABLE 2

DESCRIPTIVE STATISTICS FOR SAMPLE $(\mathrm{N}=\mathbf{2 2 2})$

\begin{tabular}{lr}
\hline \hline Percent male & 62.6 \\
Marital status & \\
$\quad$ Married & 48.6 \\
Never married & 49.1 \\
$\quad$ Divorced/separated/widowed & 2.3 \\
Age group & \\
$21-30$ & 51.8 \\
$31-40$ & 25.2 \\
$41-50$ & 12.2 \\
$51-64$ & 9.9 \\
65 and over & 0.9 \\
Highest attained formal education & \\
Less than high school & 8.1 \\
High school graduate & 34.7 \\
College (gymnasium) graduate & 17.6 \\
University graduate & 25.7 \\
Graduate degree & 14.0 \\
Work outside the home on a & \\
regular basis & 70.7 \\
Average combined monthly income & \\
for your household & \\
I am a dependent and I don't know & 12.2 \\
500 or less YTL & 17.1 \\
501-1,500 YTL & 45.5 \\
1,501-3,000 YTL & 16.7 \\
3,001-5,000 YTL & 2.7 \\
5,001 or more YTL & 5.9 \\
\hline
\end{tabular}

and then summing the responses for the five questions comprising each dimension. This resulting score is multiplied by the importance rating given by each respondent to the corresponding dimension. As can be seen, the pattern of the average importance ratings across the United States and Turkey are very similar. However, Turkish consumers report an overall lower level on the ICSM dimensions $(-20.81$ for Turkey vs. -4.51 for the United States).

This difference can be attributed, at least in part, to the developing country conditions for consumers in Turkey wherein marketing receives less emphasis (Douglas and Craig 2006). In such developing country contexts, (1) retailing environments tend to be more austere, (2) prices are higher because of distribution inefficiencies and inflation, (3) product quality tends to be less consistent, and (4) advertising tends to be executed with more of a selling orientation and less of a marketing orientation. Prahalad (2005, 79) notes that developing countries often have dual economies that include both a formal sector (where business is conducted in ways similar to the developed world) and an informal sector (where businesses, consumers, and government officials not linked by family or clan relationships frequently seek to take advantage of each other). In the absence of enforceable contract law in the informal sector of developing countries, vibrant extralegal or black markets emerge to conduct local commerce. 
TABLE 3

UNITED STATES AND TURKISH SENTIMENTS TOWARD MARKETING (STM) AND MEAN IMPORTANCE WEIGHTS FOR MARKETING FUNCTIONS

\begin{tabular}{lccc}
\hline \hline & \multicolumn{2}{c}{ Sentiments Toward Marketing } & Importance Weights Marketing Functions \\
\cline { 2 - 3 } & $\begin{array}{c}\text { United States } \\
(2001)\end{array}$ & $\begin{array}{c}\text { Turkey } \\
(2006)\end{array}$ & $\begin{array}{c}\text { United States } \\
(2001)\end{array}$ \\
\hline Overall & -4.51 & -20.81 & 4.53 \\
Product & 0.99 & 4.34 & 4.39 \\
Price & -9.56 & -16.95 & 2.73 \\
Advertising & -2.01 & -5.03 & 3.84 \\
Retail & 6.05 & -3.25 & 4.66 \\
\hline
\end{tabular}

\section{Data Analysis}

Common factor analysis was conducted with a pooled set of twenty-eight items, which included all the items measuring competencies and performance (Gerbing and Anderson, 1988). Maximum likelihood extraction with oblique rotation initially identified six factors. Steenkamp's (2004) Survey Research/Theory Testing Paradigm was employed. In this paradigm, four criteria for satisfactory results in construct identification and theory testing were employed as follows: (1) reliability (Cronbach's $\alpha>.7$ ), (2) validity (factor loadings $>.4$, with a simple structure amongst the factors), (3) overall model fit (CFI, TLI, GFI > .9; RMSEA, SRMR < $.08)$, and (4) support for hypotheses $(\mathrm{p}<.05)$.

During preliminary analysis to evaluate construct reliability, the ICSM dimensions needed item purification to attain satisfactory levels. Three of the ICSM dimensions met Steenkamp's criteria for reliability with three items each. However, the product dimension (assessing product quality) never attained this standard. In short, the respondents in the sample did not share sufficient agreement about product quality. For this reason, the items for the ICSM product dimension could not be retained in the analysis. However, the Business Provision construct was retained. In this way, an aspect of the product/service dimension of what businesses offer consumers in a commercial exchange was retained.

In the end, the remaining items from the ICSM items related to "fair pricing," "positive advertising," and "retail service." Those items that were eliminated from the analysis addressed aspects of the price, advertising and retailing dimensions that required inference (for example, "competition keeps prices reasonable"), speculation (for example, "consumers would be better off without advertising"), or strong judgments to be made (for example, "most middlemen make excessive profits"). In the end, four three-item constructs were found to have adequate reliability for inclusion in a multiple-indicator measurement model to assess the internal and external consistency of the four scales for these constructs (Gerbing and Anderson 1988).

In general, the remaining items in this analysis now focused on the front-end of the consumption process-the acquisition stage. These four constructs would then be used to derive a second-order factor to represent CATM. The final model would include the subjective QOL construct to allow assessment of convergent, discriminant, and nomological validity of the study's constructs (Hair, Anderson, and Tatham 1991). The seventeen items identifying these constructs are listed in table 4. A table of correlations among these items is included in table 5.

\section{Final Modeling}

Covariance analysis using AMOS 5 was then used to evaluate the factor structure of the twelve CATM items (Bollen 1989), and to estimate the four CATM factors and the QOL construct in a confirmatory factor analysis model. AMOS 5 minimizes a fit function between the actual covariance matrix and a covariance matrix implied by the estimated parameters from a series of structural equations for the confirmatory factor analysis model.

These incremental fit indices compare the proposed model to a baseline or null model. The Comparative Fit Index (CFI) (Bentler 1990) and the Tucker-Lewis Index (Hair, Anderson, and Tatham 1991) suggested that the comparative model fit is excellent with a CFI of .96, and a Tucker-Lewis Index of .95. Following Steenkamp's protocol, the GFI statistic (.92) and the RMSEA (.045) and the SRMR (.078) were evaluated. Each of these indicators suggested a good model had been identified. The loadings of manifest indicators on their respective latent constructs are depicted in figure 2, and all exceed Steenkamp's criteria of .4 for factor loadings. All coefficients in the confirmatory factor analysis model were statistically significant at $p=.05$.

CATM was derived by using a second-order factor analysis approach. Here, the three unidimensional ICSM factors along with the factor representing Business Provision served as the elements identifying CATM. Figure 2 depicts the results of this modeling along with the correlation of CATM with subjective QOL $(\beta=.47)$. All depicted path coefficients are statistically significant at $p=.05$. 
TABLE 4

RELIABILITIES FOR THE CONSTRUCTS IN THE FINAL MODEL

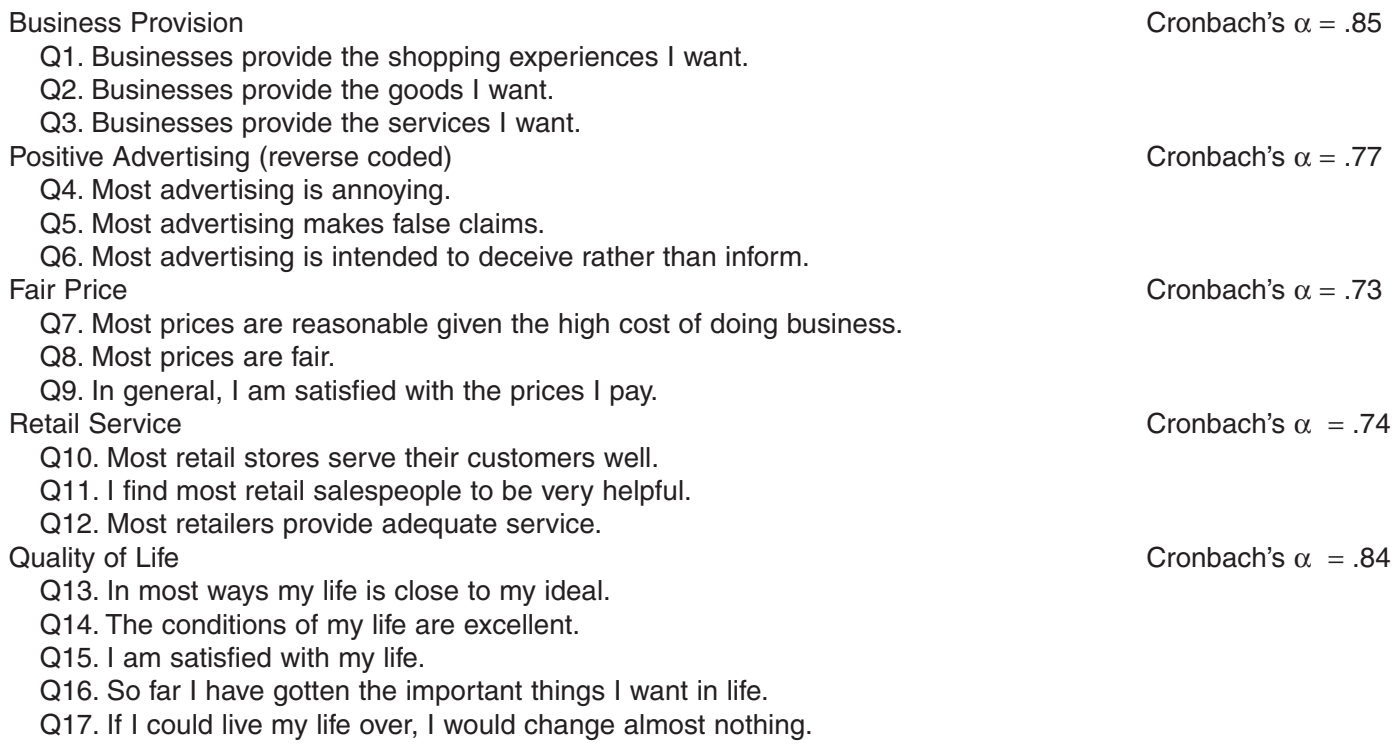

TABLE 5

CORRELATIONS OF ITEMS FOR CONSUMER ATTITUDE TOWARD MARKETING AND QUALITY OF LIFE

\begin{tabular}{|c|c|c|c|c|c|c|c|c|c|c|c|c|c|c|c|c|}
\hline & $q 1$ & $q 2$ & $q 3$ & $q 4$ & $q 5$ & $q 6$ & $q 7$ & $q 8$ & $q 9$ & $q 10$ & $q 11$ & $q 12$ & $q 13$ & $q 14$ & $q 15$ & $q 16$ \\
\hline \multicolumn{17}{|c|}{ Business Provision } \\
\hline q2 & 0.71 & & & & & & & & & & & & & & & \\
\hline q3 & 0.57 & 0.68 & & & & & & & & & & & & & & \\
\hline \multicolumn{17}{|c|}{ Positive Advertising } \\
\hline q4 & 0.19 & 0.14 & 0.13 & & & & & & & & & & & & & \\
\hline q5 & 0.10 & 0.12 & 0.08 & 0.57 & & & & & & & & & & & & \\
\hline q6 & 0.29 & 0.28 & 0.23 & 0.48 & 0.52 & & & & & & & & & & & \\
\hline \multicolumn{17}{|c|}{ Fair Pricing } \\
\hline q7 & 0.17 & 0.06 & 0.03 & 0.08 & 0.16 & 0.21 & & & & & & & & & & \\
\hline q8 & 0.09 & 0.06 & 0.09 & 0.13 & 0.20 & 0.25 & 0.45 & & & & & & & & & \\
\hline q9 & 0.19 & 0.12 & 0.14 & 0.07 & 0.16 & 0.23 & 0.51 & 0.47 & & & & & & & & \\
\hline \multicolumn{17}{|c|}{ Retail Service } \\
\hline q10 & 0.27 & 0.21 & 0.28 & 0.07 & 0.11 & 0.13 & 0.18 & 0.28 & 0.27 & & & & & & & \\
\hline q11 & 0.18 & 0.18 & 0.22 & 0.06 & 0.16 & 0.15 & 0.30 & 0.17 & 0.39 & 0.41 & & & & & & \\
\hline q12 & 0.15 & 0.18 & 0.27 & 0.09 & 0.09 & 0.06 & 0.21 & 0.24 & 0.31 & 0.57 & 0.49 & & & & & \\
\hline \multicolumn{17}{|l|}{ QOL } \\
\hline q13 & 0.16 & 0.10 & 0.11 & 0.13 & 0.16 & 0.13 & 0.14 & 0.22 & 0.24 & 0.23 & 0.09 & 0.16 & & & & \\
\hline q14 & 0.21 & 0.16 & 0.15 & 0.20 & 0.13 & 0.03 & 0.13 & 0.10 & 0.15 & 0.20 & 0.18 & 0.17 & 0.53 & & & \\
\hline q15 & 0.27 & 0.16 & 0.12 & 0.10 & 0.07 & 0.04 & 0.07 & 0.09 & 0.18 & 0.29 & 0.20 & 0.17 & 0.45 & 0.63 & & \\
\hline q16 & 0.28 & 0.17 & 0.16 & 0.17 & 0.07 & 0.08 & 0.08 & 0.07 & 0.12 & 0.22 & 0.13 & 0.13 & 0.44 & 0.58 & 0.57 & \\
\hline q17 & 0.21 & 0.14 & 0.18 & 0.10 & 0.01 & -0.04 & 0.08 & 0.11 & 0.19 & 0.26 & 0.18 & 0.20 & 0.44 & 0.45 & 0.55 & 0.52 \\
\hline
\end{tabular}

NOTE: All Pearson Product Moment correlations greater than .130 in absolute value are statistically significant at $p=.05$.

The first research question of this study focused on what would be the underlying structure of CATM. This can be answered be reviewing figure 2. As can be seen, CATM receives important contributions from each of the four CATM dimensions with strongest standardized path coefficients for Retail Service $(\beta=.77)$ and Fair Pricing $(\beta=.64)$. Business Provision $(\beta=.44)$ and Positive Advertising $(\beta=$ .37) also made moderate contributions to the derivation of CATM. In this way, the first research question is answered.
Of note, the factor loadings of the items on the four firstorder factors were much higher than those found in the Chan and Cui study (2004) (loadings ranging from .63 to .89, instead of .28 to .68). Additionally, the fit of the model was much improved over the Chan and Cui study (a CFI of .96 compared to a CFI of .82).

In sum, the seventeen items allowed for an excellent simultaneous measurement of constructs representing consumers' attitude toward performance of the marketing system 
in a developing country. As can be seen in figure 2, there is a simple structure among the items with each construct measured by its own set of three unique items. This simple structure gives evidence for both convergent validity and discriminant validity, as the proposed items for each construct load on the respective constructs and do not load on the other constructs (Bagozzi, Yi, and Phillips 1991). The confirmatory factor analysis model suggests convergent validity of the items included in the model because the items of the same constructs share a relatively high degree of the variance of their respective underlying constructs, as indicated by the factor loadings being statistically significant at $p=.05$. The internal consistency of each construct is also evidenced by the face validity or conceptual relatedness of the items. For example, the fair pricing construct is comprised of items related to fair pricing. Together, these results suggest compelling evidence for the underlying structure of CATM in the context of a developing country found in this study.

The second research question of this study focused on whether CATM and QOL were distinct constructs. Discriminant validity for the constructs in the final model is suggested by the items for each construct having factor loadings which are not statistically significant at $p=.05$, with conceptually similar, but distinct constructs (Bagozzi, Yi, and Phillips 1991). In other words, the items representing one construct do not also represent another construct to a high degree. Therefore, RQ2 is answered in the affirmative, as the second-order factor CATM and the QOL construct manifest the same discriminant validity for each other as they do for Retail Service, Fair Pricing, Business Provision, and Positive Advertising.

The third research question of the study focused on how CATM and QOL might be related. Nomological validity for the CATM construct is evidenced by the moderate-sized correlation of the second-order factor for CATM with QOL ( $r=$ .47). This suggests that as CATM improves one unit, then QOL would likely improve .47 of a unit. Likewise, as CATM declines one unit, then QOL would likely decline .47 of a unit. In sum, CATM and QOL have a healthy and positive relationship. This is a major contribution of this research study.

\section{DISCUSSION}

In their assessment of challenges for marketing scholars, Day and Montgomery (1999) named the first challenge as providing meaningful measures, inferences and calibration. Recently, Venkatesh and Peňaloza (2006) have called for researchers to take a larger focus in their work by researching "markets" instead of what might be relevant only to firms, such as consumers of individual product categories or customers of firms. This study has taken such a recommended focus. Specifically, this study has looked at consumers' views of marketing practice in the Aggregate Marketing System and has further developed meaningful measures of CATM by identifying a second-order factor structure for this construct. By using a rigorous approach for survey research and theory testing, researchers now have a set of measures that can be used in a variety of other settings. In developing countries, researchers can use these measures with confidence because these measures were operationalized and evaluated in the context of a developing country.

For researchers of marketing in developing countries, this study not only provides valuable insight into how consumers in a developing country regard marketing practices offered in their Aggregate Marketing System, but also valuable insight into the relationship of CATM with QOL. A simultaneous multi-item measurement of both constructs was accomplished using a rigorous confirmatory factor analysis approach. The theoretical implications of this study should guide QOL researchers in integrating CATM into future theories of QOL-marketing-especially those intended for broad application that would include developing countries. Given the accelerated move of developing countries into global markets in what Friedman (2006) terms a "flattening" of the world, the results of this study are particularly germane to future endeavors of marketers and researchers.

More steps of theory building and testing in the realm of QOL and its elements still remain. Looking to the future, the strong results for the model in figure 2 offer promise for this model to serve as a foundational piece in future theory development efforts for CATM and QOL marketing. For example, while this study focused on CATM, adding items to measure the other stages of consumption could be done to broaden understanding of CWB. For example, in such an effort including items for the disposal dimension of consumption and the same confirmatory factor analysis approach of this study, the factor structure for the CATM dimensions would not change. In this way, the confirmatory factor analysis approach would allow other dimensions to be included in an additive fashion without disturbing the underlying factor structure of the CATM construct and the four dimensions that contribute to it.

This nomological network for the constructs of this study can be better understood within the context of the full structural equation model where certain constructs are posited to be causally antecedent to other dependent constructs (Malhotra 2004). Substantive issues, such as whether CATM is a causal determinant of QOL could then be examined. Insights from this study bring researchers to the threshold of this important research.

\section{Limitations}

The current study is cross-sectional and was conducted in a single developing country, using self-reported, subjective measures of CATM and QOL. Although the generalizability 


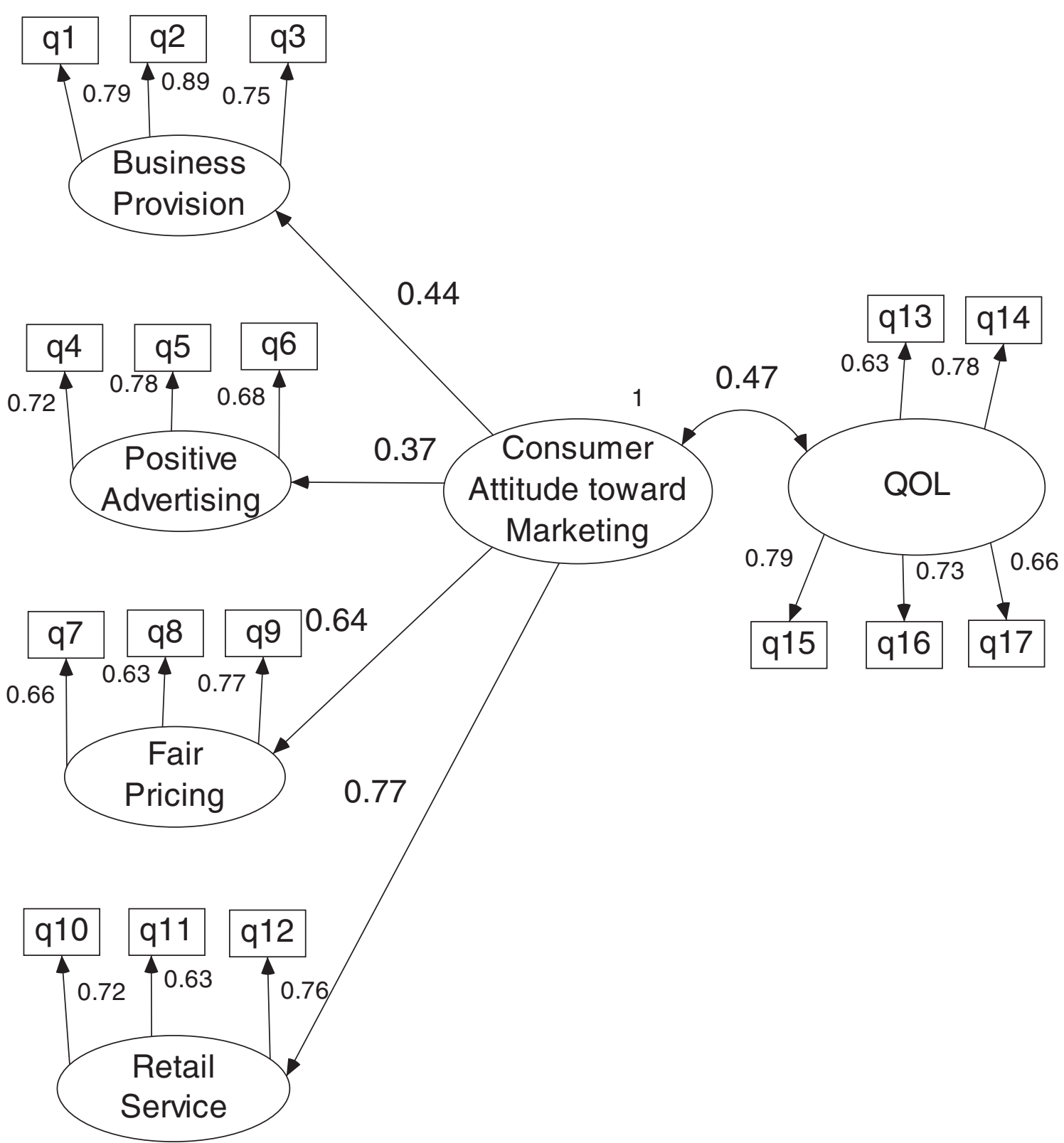

FIGURE 2 CONFIRMATORY FACTOR ANALYSIS MODEL FOR CONSUMER ATTITUDE TOWARD MARKETING AND QOL

NOTE: Comparative Fit Index $(\mathrm{CFI})=.96$; Tucker-Lewis Index = .95; Root Mean Square Residual = .04; All coefficients statistically significant at $p<.05$.

of findings of single-country studies has some limits, a highly desirable feature of such studies is that they provide a much greater degree of control over market and environmental peculiarities. Additional empirical research is needed to determine if the scales developed in this study are generalizable to other country contexts.

\section{Conclusion}

This study was able to use a second-order factor approach in defining CATM. Because of this success, the study's researchers were able to assess the discriminant and convergent validity for an important construct related to consumer experience and CWB in a developing country. In the future, researchers can use the measures this study's researchers have developed and the methods they have employed to progressively build substantive understanding about CATM and QOL-marketing.

\section{REFERENCES}

Bagozzi, R. P., Y. Yi, and L. W. Phillips. 1991. Assessing construct validity in organizational research. Administrative Science Quarterly 36:421-58. 
Bentler, P. M. 1990. Comparative fit indexes in structural models. Psychological Bulletin 107:238-46.

Bollen, K. A. 1989. Structural equations with latent variables. New York, NY: John Wiley \& Sons.

Burroughs, J. E., and A. Rindfleisch. 2002. Materialism and well-being: A conflicting values perspective. Journal of Consumer Research 29 (December): 348-70.

Chan, E., O. Yau, and R. Chan R. 1990. Consumer sentiment in Australia: A replication and cross-national comparison. European Journal of Marketing 24 (10): 44-58.

Chan, Tsang-Sing, and Geng Cui. 2004. Consumer attitudes toward marketing in a transitional economy: A replication and extension. Journal of Consumer Marketing 21 (1): 10-26.

Davis, I. 2005. The biggest contract. The Economist. May 28.

Day, G. S., and D. Montgomery. 1999. Charting new directions for marketing. Journal of Marketing 63 (Special Issue): 2-13.

Diener, E., R. A. Emmons, R. J. Larsen, and S. Griffin 1985. The satisfaction with life scale. Journal of Personality Assessment 49 (1): 71-75.

Diener, E., and E. M. Suh 1999. National differences in subjective wellbeing. In Well-Being: The foundations of hedonic psychology, edited by D. Kahneman, E. Diener and N. Schwarz. New York: Russell Sage Foundation.

Dixon, D. F. 1984. Macromarketing: A social systems perspective. Journal of Macromarketing 3:4-17

Douglas, S. P., and C. S. Craig. 2006. Expanding the perspective: Making U.S. marketing relevant for the new world order. In Does marketing need reform?: Fresh perspectives on the future, edited by J. N. Sheth and R. S. Sisodia, 217-21. Armonk, NY: M. E. Sharpe.

Fisk, G. 1981. An invitation to participate in affairs of the Journal of Macromarketing. Journal of Macromarketing 1 (Spring): 3-7.

Friedman, T. L. 2006. The world is flat: A brief history of the twenty-first century. Updated and expanded edition. New York: Farrar, Strauss and Giroux.

Gaski, J. F., and M. J. Etzel 1986. The index of consumer sentiment toward marketing. Journal of Marketing 50 (July): 71-81.

- 2005. National aggregate consumer sentiment toward marketing: A thirty-year retrospective and analysis. Journal of Consumer Research 31 (March): 859-67.

Gerbing, D. W., and J. C. Anderson. 1988. An updated paradigm for scale development incorporating unidimensionality and its assessment. Journal of Marketing Research XXV (May): 186-92.

Hair, J. F., Jr., R. E. Anderson, and R. L. Tatham. 1991. Multivariate data analysis. New York, NY: MacMillan.

Karababa, E. 2005. The evaluation of Turkish marketing and consumption behavior. In Marketing management in Turkey: Cases and challenges, edited by D. N. Thompson. Gazi Kitabevi, 11-18.

2006. Origins of a consumer culture in alternative early modern context: Ottoman Bursa. Unpublished dissertation, Bilkent University.

Klein, T. A., and R. W. Nason. 2000. Marketing and development: Macromarketing perspectives. In Handbook of marketing and society, edited by P. Bloom and G. T. Gundlach. Thousand Oaks, CA: Sage.

Lee, D. J., M. J. Sirgy, V. Larsen, and N. D. Wright. 2002. Developing a subjective measure of consumer well-being. Journal of Macromarketing 22 (2): $158-169$

Malhotra, N. K. 1981. A scale to measure self-concepts, person concepts, and product concepts. Journal of Marketing Research XVIII (November): 456-64.

. 2004. Marketing research: An applied orientation, Fourth edition. Upper Saddle River, NJ: Prentice Hall.
2006. Consumer well-being and quality of life: An assessment and directions for future research. Journal of Macromarketing 26 (1): 77-80.

Malhotra, N. K., J. Agarwal, and M. Peterson. 1996. Methodological issues in cross-cultural research: A state-of-the-art review. International Marketing Review 13 (5): 7-43.

McCarthy, J. 1960. Basic marketing: A managerial approach. Homewood, IL: Richard D. Irwin.

Nason, R. W., and P. D. White. 1981. The visions of Charles C. Slater: Social consequences of marketing. Journal of Macromarketing 1 (Fall): 4-18.

Prahalad, C. K. 2005. The fortune at the bottom of the pyramid: Eradicating poverty through profits. Upper Saddle River, NJ: Wharton School Publishing.

Sirgy, M. J., and D. J. Lee. 2006. Macro measures of consumer well-being (CWB): A critical analysis and a research agenda. Journal of Macromarketing 26 (1): 27-44.

Sirgy, M. J., D. J. Lee, A. C. Michalos, A. L. Ferriss, R. A. Easterlin, D. Patrick, and W. Pavot. 2006. The quality-of-life (QOL) research movement: Past, present, and future. Social Indicators Research 76:343-466.

Sirgy, M. J., D. J. Lee, C. Miller, and J. E. Littlefield. 2004. The impact of globalization on a country's quality of life: Toward an integrated model. Social Indicators Research 68:251-98.

Slater, C., D. Henley, J. Wish, V. Farace, L. Jacobs, D. Lindley, A. Mercadeo, and M. Moran. 1969. Market processes in La Paz, Bolivia. East Lansing: Latin American Studies Center, Michigan State University.

Steenkamp, Jan-Benedict E. M. 2004. The survey research/theory testing paradigm. 2004 SMA Distinguished Scholar Presentation, Society for Marketing Advances Conference, November 4, St. Petersburg Beach, FL.

UNDP. 2006. Human development report 2006. New York: United Nations Development Program, 284.

Varadarajan, P. R., and P. N. Thirunarayana. 1990. Consumers' attitudes towards marketing practices, consumerism, and government regulations: Cross-national perspectives. European Journal of Marketing 24 (6): 6-23.

Venkatesh, A., and L. Peňaloza. 2006. From marketing to the market: A call for paradigm shift. In Does marketing need reform?: Fresh perspectives on the future, edited by J. N. Sheth and R. S. Sisodia, 134-50. Armonk, NY: M. E. Sharpe.

Wee, C. H., and Chan, M. 1989. Consumer sentiment towards marketing in Hong Kong. European Journal of Marketing 23 (4): 25-39.

Wilkie, W. 2006. The world of marketing thought: Where are we heading? In Does marketing need reform?: Fresh perspectives on the future, edited by J. N. Sheth and R. S. Sisodia, 239-47. Armonk, NY: M. E. Sharpe.

Wilkie, W., and E. S. Moore. 2006. Macromarketing as a pillar of marketing thought. Journal of Macromarketing 26 (2): 224-32.

World Bank. 2003. World development indicators. Washington, DC: World Bank.

Mark Peterson is an associate professor of marketing at the University of Wyoming. His research interests include methods, international marketing, as well as marketing and society issues.

Ahmet Ekici is an assistant professor of marketing at Bilkent University. His research interests include macromarketing issues, such as consumer well-being, as well as consumer trust for societal institutions. 